\title{
Coaching y PNL para frenar el Mobbing o Acoso Laboral
}

Por Mario Cañas, Máster en Coaching y PNL/CPA/Especialista en Habilidades Directivas·mario.canas.coach@gmail.com

n Estados Unidos, y en el resto de Europa, la palabra Bullying se usa únicamente en relación con las situaciones de acoso producidas en la escuela, entre niños o adolescentes, y el término Mobbing cuando estas conductas se producen en los lugares de trabajo.

El fenómeno del Mobbing consiste en humillar y hostigar de modo verbal o físico, por parte de un jefe con poder hacia otro trabajador con menos poder, o de un grupo de colaboradores de trabajo hacia un compañero en específico, sin la intervención de un superior. Este desequilibrio de poder entre los trabajadores es la característica más relevante, con independencia de la edad, sexo o del tipo de conductas específicas.

El Acoso Laboral es una serie de comportamientos negativos repetidos y persistentes de un jefe o superior hacia uno o más individuos, que implica un desequilibrio de poder y crea un ambiente de trabajo hostil. Entendiendo por acoso laboral: hostigar, ofender, excluir socialmente a alguien o interferir negativamente en sus tareas.

El Mobbing no es lo mismo que acoso laboral, pero para efectos de este artículo lo retrataré como un fenómeno social similar, que está experimentando un notable auge en la sociedad actual del mundo, donde El Salvador no es la excepción.

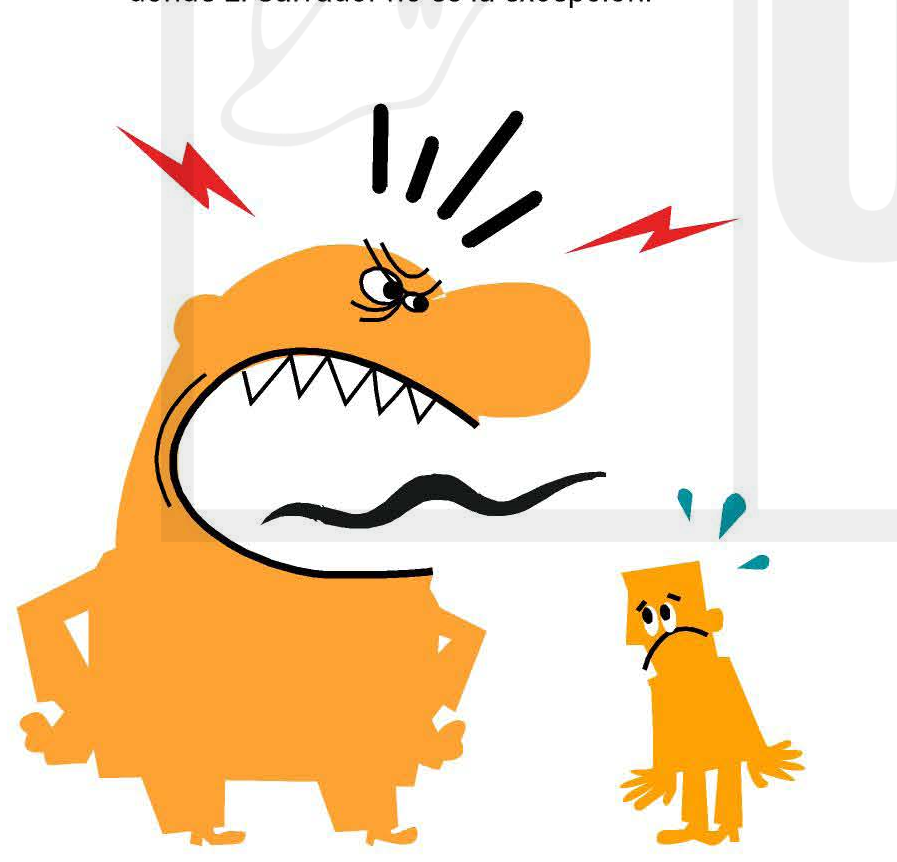

El incremento de los casos de acoso en el trabajo o Mobbing es consecuencia, en gran parte, del período de crisis económica y conflictos sociales en los que estamos inmersos desde hace años. Incluso al buscar datos estadísticos sobre este tema, no existe mucha información y se confunde con el acoso sexual, lo cual no es lo mismo.

La falta de información detallada y suficiente del tema es propiciado por el desconocimiento de los derechos laborales y la dictadura de algunos Jefes, con criterios de administradores de animales o esclavos. Esto hace que todo ello contribuya a una mayor impunidad de quienes ejercen una violencia psicológica extrema en el tema laboral.

El Acoso Laboral o Mobbing es entendido como el fenómeno en el que una persona o grupo de personas ejerce una violencia psicológica extrema, de forma sistemática y recurrente, -al menos una vez por semana-, y durante un tiempo prolongado, -más de seis meses-, sobre otra persona en el lugar del trabajo. La finalidad de ello es destruir la reputación de la víctima, las redes de comunicación, perturbar el ejercicio de sus laborares y lograr finalmente que esa persona o grupo de personas acaben abandonando el lugar de trabajo.

\section{Cómo identificar si está sufriendo Acoso Laboral o Mobbing en el trabajo}

Si de forma continua y repetitiva se siente identificado con una o con varias de las siguientes afirmaciones, es posible que esté viviendo un problema de acoso en el trabajo:

- Constantemente me encuentro atacado, despreciado o perjudicado por las actuaciones de otra persona o grupo de personas

- Siente que no puede actuar o hablar con libertad, porque cualquier cosa que diga o que haga es utilizada en su contra

- Le critican y ponen malas caras ante cualquier decisión que tome

- Intentan arrebatarle cualquier cosa que le dé un poco de felicidad en esta vida

- Cambian mal intencionadamente el significado de las cosas que dice

- Le aíslan o hacen sentirle vacío

- Le insultan y/o me desprecian ante terceras personas

- Difunden rumores acerca de usted

- Le amenazan, coaccionan, o hacen gesto intimidatorio

- No pide grandes cosas. Sólo quiere que lo dejen vivir o laborar en paz. 
Los sentimientos acumulados por la víctima al vivir siendo acosado laboralmente, tras un período prolongado de maltrato (en un número importante de los casos) siente un enorme sentimiento de "culpa". Esta piensa que los problemas que le surgen en el trabajo (los ataques continuos, las burlas, las críticas hacia su profesionalidad, entre otros) son consecuencia de sus errores y por lo tanto exclusivamente achacables a su responsabilidad individual. Las víctimas en ocasiones se comportan intentando resolver estas situaciones aversivas mostrándose sumisas hacia el acosador, y pensando que el problema acabará resolviéndose solo.

Lo anterior está lejos de la realidad. Si no somos capaces de aprender a defender nuestra dignidad y hacernos respetar, el acoso no cesará e irá a más.

Coaching y un poco de Programación Neurolengüistica (PNL) en la intervención en los procesos de acoso laboral.

El Principal propósito del Coaching es ayudar a la persona acosada, a efecto que entienda que ella no es culpable de la situación que está viviendo, sino que es una víctima de la misma.

A partir de ese punto, el Coach facilita, a lo largo del proceso que la persona vuelva a retomar el control y la responsabilidad sobre su persona con el fin de que pueda vivir mejor y solventar la situación aversiva que le supone ir a trabajar a diario.

El Coaching es una metodología eficaz para lograr alcanzar estos objetivos. El coaching ayuda a diagnosticar cuál es su situación actual y que quiere conseguir o lograr, trazar un plan de acción, y ponerle manos a la obra para alcanzar los objetivos definidos. El coaching facilita hacer cosas diferentes para lograr resultados diferentes. Es proactividad, despierta mis fortalezas y recursos.

La intervención de problemas de acoso con la combinación de técnicas y métodos procedentes del Coaching y de la PNL, (con las técnicas clásicas procedentes de la Inteligencia Emocional) ofrecen un nivel significativamente mayor de éxito.

Dicho lo anterior, es importante realizar las siguientes actividades para superar el acoso laboral o mobbing:

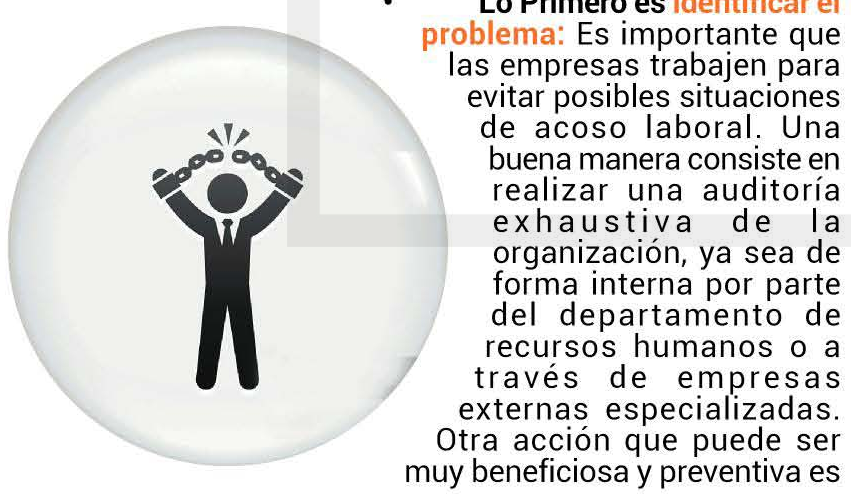

realizar cursos formativos en la empresa para los trabajadores para que conozcan la temática y estén familiarizados con este tipo de conflictos y así poder combatirlos de manera más eficaz. Por su parte, el trabajador debe estar informado por su propia cuenta del problema. De esta forma, será más fácil de identificar y así solucionar.

- Documente y registre las agresiones desde el inicio: De cara a una posible demanda judicial, es vital tener documentación física que pueda avalar nuestro testimonio. De esta manera tendrá más herramientas para poder negociar con la empresa para una resolución satisfactoria. También es muy importante hacer públicas las agresiones que se reciben en la intimidad y comunicarlas a compan̄eros, amigos, pareja, etc.

- Controle y canalice la ira: Nuestras posibles explosiones de ira y el resentimiento son los aliados naturales del acosador. Cuando perdemos los nervios el acosador ha conseguido justo lo que buscaba y nos debilita personalmente, nos hace perder credibilidad delante de nuestro entorno. Por lo tanto, debemos trabajar para desactivarnos emocionalmente y así evitar reaccionar de ninguna forma ante los ataques.

- Haga frente al problema: El acosador, en el fondo, es cobarde y débil, necesita adoptar una posición hostigadora para así sentirse fuerte. Debemos afrontar el Mobbing asertivamente y de forma directa, pues es la única forma de hacer retroceder al hostigador o, en todo caso, protegernos emocionalmente y defender nuestros derechos y así mantener nuestra dignidad y autoestima. Por lo tanto, debemos dar respuesta a las calumnias y críticas destructivas con asertividad, ni pasiva ni agresivamente.

- Proteger y guardar bajo llave los datos, archivos y documentos de nuestro trabajo: El hostigador puede intentar manipular estos datos en nuestra contra. Debemos desconfiar en todo momento del acosador sin llegar a obsesionarnos con ello. Al mismo tiempo, es importante evitar el aislamiento social el cual puede fomentar el empeoramiento de la situación. Debemos salir y afrontar socialmente la situación del acoso.

- Rechazar la inculpación del acosador: Antes de aceptar la culpabilidad analicemos la situación objetivamente, no nos culpemos sin más, justificando los agravios recibidos. Tampoco intentemos convencer o cambiar al hostigador, pues seguramente no quiere convencerse de nada. Cuando una persona ataca nuestros derechos y opta por agredirnos, no hay diálogo que valga. Los individuos solo cambiamos cuando queremos o podemos, por lo tanto no intentemos enseñar a quién nos acosa.

- Desde el principio, es importante solicitar sesiones profesionales y personalizadas de Coaching y en definitiva, el apoyo de un consejero legal: Es la mejor forma de estar preparados y defender nuestros derechos. 